\title{
Intranasal drugs for analgesia and sedation in children admitted to pediatric emergency department: a narrative review
}

\author{
Valeria Pansini ${ }^{1 \#}$, Antonietta Curatola ${ }^{2 \#}$, Antonio Gatto ${ }^{1}$, Ilaria Lazzareschi ${ }^{2}$, Antonio Ruggiero ${ }^{3}$, \\ Antonio Chiaretti ${ }^{2}$
}

${ }^{1}$ Dipartimento di Pediatria, Fondazione Policlinico Universitario “A. Gemelli” IRCCS, Roma, Italia; ${ }^{2}$ Dipartimento di Pediatria, Fondazione Policlinico Universitario “A. Gemelli” IRCCS, Università Cattolica del Sacro Cuore, Roma, Italy; ${ }^{3}$ Pediatric Oncology Unit, Fondazione Policlinico Universitario “A. Gemelli” IRCCS, Università Cattolica Sacro Cuore, Rome, Italy

Contributions: (I) Conception and design: A Chiaretti, A Ruggiero; (II) Administrative support: A Curatola; (III) Provision of study materials or patients: A Curatola, V Pansini; (IV) Collection and assembly of data: A Curatola, V Pansini, A Gatto; (V) Data analysis and interpretation: A Curatola, V Pansini, A Gatto, I Lazzareschi; (VI) Manuscript writing: All authors; (VII) Final approval of manuscript: All authors.

\#These authors contributed equally to this work.

Correspondence to: Antonietta Curatola. Dipartimento Scienze della Salute della Donna, del Bambino e di Sanità Pubblica, UOC Pediatria, Fondazione Policlinico Universitario “A. Gemelli” IRCCS, Roma, Italy. Email: c.anto91@libero.it.

\begin{abstract}
Acute pain is one of the most common symptoms in children admitted to the Pediatric Emergency Department (PED) and its management represents a real clinical challenge for pediatricians. Different painful procedures can be very stressful for young children and their perception of pain can be enhanced by emotional factors, such as anxiety, distress, or anger. Adequate procedural sedation reduces anxiety and emotional trauma for the patient, but it reduces also stress for operators and the time for procedures. We have reviewed the literature on this topic and the drugs covered in these papers were: midazolam, fentanyl, ketamine, and dexmedetomidine. There are several routes of administering for these drugs to provide analgesia and anxiolysis to children: oral, parenteral, or intranasal (IN). Intravenous (IV) sedation, since it involves the use of needles, can be stressful; instead, IN route is a non-invasive procedure and generally well tolerated by children and it has become increasingly widespread. Some medications can be administered by a mucosal atomizer device (MAD) or by drops. The benefits of the atomized release include less drug loss in the oropharynx, higher cerebrospinal fluid levels, better patient acceptability, and better sedative effects. IN midazolam has a sedative, anxiolytic and amnesic effect, but without analgesic properties. Fentanyl and ketamine are mainly used for pain control. Dexmedetomidine has anxiolytic and analgesic properties. In conclusion, IN analgo-sedation is a simple, rapid and painless option to treat pain and anxiety in the PED requiring brief training on the administration process and experience in sedation.
\end{abstract}

Keywords: Analgo-sedation; intranasal (IN); mucosal atomizer device (MAD); Pediatric Emergency Department (PED)

Submitted Jul 07, 2020. Accepted for publication Aug 14, 2020.

doi: 10.21037/atm-20-5177

View this article at: http://dx.doi.org/10.21037/atm-20-5177

\section{Introduction}

Acute pain is one of the most common symptoms of children admitted to the Pediatric Emergency Department and its management represents an important clinical issue for physicians and healthcare providers. Different painful procedures, such as laceration repair, extremities fractures, incision and drainage, but also simply the placement of an intravenous (IV) catheter, can be distressful to young children and their parents. Moreover, child's pain perception can be increased by some emotional factors, such as elevated anxiety, distress, anger and low mood. This can 
make subsequent medical procedures and pain management more difficult (1).

Moreover, the undertreated pain could affect the child's mental health long-term, resulting in detrimental psychological effects, negative lasting memories and possibly exaggerated responses to future painful clinical episodes (2).

In this regard, pain management in pediatric age is often inadequate, despite the availability of consensus guidelines on this topic in emergency medicine (2). Different studies show that adults receive treatment for their pain much more than pediatric patients $(3,4)$. This could be due to children's inability at times to verbally express their symptoms, but also to the fear of paediatricians to prescribe opioids to children, lack of formal training regarding opioid medication choice and the fear of adverse drug reactions (5-7).

The benefits of providing adequate procedural sedation for children include decreasing patient anxiety and emotional trauma, decreasing parental emotional discomfort, and completion of the procedure (8), reducing stress for operators and shortening the time of procedure duration.

There are different routes of drug administration to provide analgesia and anxiolysis to children: oral, parenteral or intranasal (IN) route. Oral administration has a slower onset of action and is related to the cooperation of the child (9). The parenteral route requires intramuscular administration or placement of an IV catheter, which can be painful and anxiety for the child and require a person who is able to quickly and effectively place an IV catheter (9). However, this is a safe route that can provide rapid and almost immediate analgesia. IN administration is easy, non-invasive and usually well tolerated by children, while the drugs intranasally delivered have a rapid onset of action and high bioavailability (10).

Different drugs have been used for procedural IN sedation in pediatric age.

Midazolam is a $\gamma$-aminobutyric acid (GABA) receptor inhibitor and it is the most frequently used premedication in paediatrics $(11,12)$, due to its sedative, anxiolytic, and amnesic effect. It can be administered intranasally; however, it hasn't analgesic properties and may be associated with side effects, such as paradoxical reactions, restlessness, and behavioural changes $(13,14)$. In the last years, attention on other drugs with analgesic and sedative properties is increasing, particularly on fentanyl, ketamine and dexmedetomidine, which can be also administered by the IN route.

Absorption of intranasally administered drugs depends on anatomical properties, as well as specific properties of the drug involved. About the $3-5 \%$ of surface area in the nasal cavity is covered by the olfactory epithelium, that can offer direct access to the central nervous system (CNS) (15).

The time that a drug is in direct contact with the nasal mucosa affects how much it is absorbed (16). The drug absorption occurs within 30 minutes from the IN administration; then the remaining drug may be eliminated by the mucociliary apparatus (17). Volumes of $0.3 \mathrm{~mL}$ or less for nostril are easily tolerated; larger volumes are contraindicated as the drug ends up in the nasopharynx. Besides, drug absorption depends also on properties of drug involved, such as its molecular weight, lipophilicity, and electrical charge (16).

There are two ways to administer IN medications: by dripping or atomization. The first doesn't require other equipment in addition to a syringe but a compliant child is necessary. In the last years, the mucosal atomizer device (MAD) is the most used IN delivery device that breaks medications into smaller, easily absorbed particles and administers them in a relatively rapid fashion (18).

We present the following article in accordance with the Narrative Review reporting checklist (available at http:// dx.doi.org/10.21037/atm-20-5177).

\section{Methods}

We made a review of the literature about this topic using PubMed with various search terms. The keywords used were: intranasal, intranasal sedation, intranasal analgesia, intranasal fentanyl, intranasal midazolam, intranasal dexmedetomidine, intranasal ketamine, pain and emergency care. We included randomized controlled trials (RCTs), prospective studies, observational studies and retrospective studies involving patients aged 0 to 18 years, who received IN administration of different analgesic and sedative drugs. The exclusion criteria were: reviews, case reports, case series, studies involving patients older than 18 .

\section{Results}

We have reviewed and included in this paper more relevant clinical studies, in particular retrospective and prospective studies and RCTs. The data of RCT are summarized in Table 1 and those of prospective and retrospective studies in Tables 2,3. These studies had a variable duration between 6 months and 3 years and the median number of subjects enrolled was 90 . 
Table 1 Randomized controlled trials for treatment of acute pain with intranasal drugs

\begin{tabular}{|c|c|c|c|c|c|c|}
\hline Authors & Year & Subjects & $\begin{array}{c}\mathrm{N}^{\circ} \text { of } \\
\text { subjects }\end{array}$ & Dose & Procedures & Conclusions \\
\hline Patel et al. & 2018 & 4 to $9 \mathrm{yrs}$ & 44 & $\begin{array}{l}\text { IND } 2 \text { or } 2.5 \mathrm{mcg} / \mathrm{kg} \text {; } \\
\text { OD } 4 \text { or } 5 \mathrm{mcg} / \mathrm{kg}\end{array}$ & Dental services & $\begin{array}{l}D \text { is a safe and effective agent for PS } \\
\text { and IND is better than OD }\end{array}$ \\
\hline Li et al. & 2019 & $\begin{array}{l}1 \text { to } 12 \text { yrs with } \\
\text { suspected ASD }\end{array}$ & 278 & $\begin{array}{l}\text { IND } 3 \mathrm{mcg} / \mathrm{kg} \text {; OMDZ } \\
0,2 \mathrm{mg} / \mathrm{kg}\end{array}$ & $\begin{array}{l}\text { Head CT scan and/or } \\
\text { ABR examination }\end{array}$ & $\begin{array}{l}\text { IND + OMDZ vs. IND solo: > sedation } \\
\text { success rate, without increase in } A E\end{array}$ \\
\hline Miller et al. & 2018 & 3 to 24 months & 280 & $\begin{array}{l}\text { IND } 2.5 \mathrm{mcg} / \mathrm{kg} ; \text { OPENT } \\
5 \mathrm{mg} / \mathrm{kg}\end{array}$ & TTE & $\begin{array}{l}\text { IND is comparable to OPENT sedation } \\
\text { without increase the risk of important } \\
\text { AE. IND appears to be an effective } \\
\text { "rescue" sedative for both failed OPENT } \\
\text { and IND sedation }\end{array}$ \\
\hline $\begin{array}{l}\text { Sathyamoorthy } \\
\text { et al. }\end{array}$ & 2019 & $\begin{array}{l}>5 \mathrm{yrs} \text { and } \\
>20 \mathrm{~kg} \text { (difficult } \\
\quad \text { children) }\end{array}$ & 75 & $\begin{array}{l}\text { OMDZ } 0.5 \mathrm{mg} / \mathrm{kg}(\mathrm{max} \\
15 \mathrm{mg}) ; \text { IND } 2 \mathrm{mcg} / \mathrm{kg} \\
(\max 100 \mathrm{mcg})\end{array}$ & Dental procedures & $\begin{array}{l}\text { IND vs. OMDZ: > success rate in } \\
\text { sedation and parental separation }\end{array}$ \\
\hline Quinn et al. & 2018 & $\begin{array}{l}3 \text { to } 17 \mathrm{yrs} \\
<64 \mathrm{~kg}\end{array}$ & 22 & $\begin{array}{l}\text { INK } 1 \mathrm{mg} / \mathrm{kg} \text { vs. of INF } \\
1.5 \mu \mathrm{g} / \mathrm{kg}\end{array}$ & $\begin{array}{l}\text { Musculoskeletal injury } \\
\text { and abdominal } \\
\text { pathologies }\end{array}$ & $\begin{array}{l}\text { INK = INF in relieving pain post } 20^{\prime} \text { after } \\
\text { administration; INK }<\text { INF in relieving } \\
\text { pain post } 10^{\prime} \text { after administration }\end{array}$ \\
\hline Frey et al. & 2019 & 8 to $17 \mathrm{yrs}$ & 90 & $\begin{array}{l}\text { INK } 1.5 \mathrm{mg} / \mathrm{kg} \text { vs. } \\
\text { INF: } 2 \mu \mathrm{g} / \mathrm{kg}\end{array}$ & Acute extremity injuries & $\begin{array}{l}\text { INK = INF in relieving pain; INK had an } \\
\text { increase in minor and transient } \mathrm{AE}\end{array}$ \\
\hline Seiler et al. & 2019 & 2 to 16 yrs & 402 & INF $1.5 \mathrm{mcg} / \mathrm{kg}$ & $\begin{array}{l}\text { Procedural } \\
\text { analgosedation }\end{array}$ & $\begin{array}{l}\mathrm{N}_{2} \mathrm{O} 70 \%+\mathrm{INF} \text { vs. } \mathrm{N}_{2} \mathrm{O} 70 \% \text { solo: } \\
\text { no difference in sedation depth and } \\
\text { relieving pain, but < incidence of } \\
\text { vomiting }\end{array}$ \\
\hline Nielsen et al. & 2013 & $\begin{array}{l}0.8 \text { to } 17 \mathrm{yrs} \\
\text { weight }>10 \mathrm{~kg}\end{array}$ & 50 & $\begin{array}{l}\text { INSUF } 0.5 \mathrm{mcg} / \mathrm{kg}+ \\
\text { INK } 0.5 \mathrm{mg} / \mathrm{kg} \text { (nasal } \\
\text { spray) }\end{array}$ & $\begin{array}{l}\text { Insertion of PVA, } \\
\text { removal of chest tube, } \\
\text { cleaning of minor } \\
\text { burns, and dressing } \\
\text { change of abscess }\end{array}$ & $\begin{array}{l}\text { INSUF + INK: rapid onset of analgesia } \\
\text { with few AE }\end{array}$ \\
\hline
\end{tabular}

D, dexmedetomidine; MDZ, midazolam; K, ketamine; IND, intranasal dexmedetominidine; OD, oral dexmedetominidine; OMDZ, oral midazolam; CT, computerized tomography; AE, adverse events; OK, oral ketamine; OPENT, oral pentobarbital; TTE, transthoracic echocardiography; $\mathrm{OCH}$, oral chloral hydrate; INK, intranasal ketamine; INF, intranasal fentanyl; OK, oral ketamine; INSUF, intranasal sufentanil; INM, intranasal midazolam. 
Table 2 Prospective studies for treatment of acute pain with intranasal drugs

\begin{tabular}{|c|c|c|c|c|c|c|}
\hline Authors & Year & Subjects & $\begin{array}{c}\mathrm{N}^{\circ} \text { of } \\
\text { subjects }\end{array}$ & Dose & Procedures & Conclusions \\
\hline Nemeth et al. & 2019 & 0 to $17 \mathrm{yrs}$ & 100 & $\begin{array}{l}\text { INMDZ } 0.5 \text { mg/kg; INF } \\
2 \mathrm{mcg} / \mathrm{kg} ; \text { INK } 4 \text { mg/kg }\end{array}$ & $\begin{array}{l}\text { APT for fractures, } \\
\text { burns and scalds }\end{array}$ & $\begin{array}{l}\text { A protocol for analgosedation using INF, } \\
\text { INK, INMDZ, alone or in combination, was } \\
\text { effective and safe }\end{array}$ \\
\hline Yenigun et al. & 2018 & 2 to $14 \mathrm{yrs}$ & 63 & $\begin{array}{l}\text { IVPARA } 10 \text { mg/kg ×3/day; } \\
\text { INK } 1.5 \mathrm{mg} / \mathrm{kg} \times 3 / \text { day; INF } \\
1.5 \mathrm{mcg} / \mathrm{kg} \times 3 / \text { day }\end{array}$ & $\begin{array}{l}\text { Postoperative } \\
\text { pain relief after } \\
\text { tonsillectomy }\end{array}$ & $\begin{array}{l}\text { INK or INF vs. IVPARA: more effective for } \\
\text { postoperative analgesia }\end{array}$ \\
\hline Alp et al. & 2019 & 9-36 months & 217 & $\begin{array}{l}\text { INMDZ } 0.2 \text { mg/kg; INK } \\
4 \text { mg/kg; OCH } 50 \text { mg/kg }\end{array}$ & TTE & $\begin{array}{l}\text { INMDZ = INK = OCH in sedation success } \\
\text { rate; INMDZ has the most rapid onset of } \\
\text { sedation; INK has the shortest duration of } \\
\text { sedation }\end{array}$ \\
\hline
\end{tabular}

TTE, transthoracic echocardiography; OCH, oral chloral hydrate; INK, intranasal ketamine; INF, intranasal fentanyl; INMDZ, intranasal midazolam; APT, acute pain therapy; IVPARA, intravenous paracetamol.

Table 3 Retrospective studies for treatment of acute pain with intranasal drugs

\begin{tabular}{|c|c|c|c|c|c|c|}
\hline Authors & Year & Subjects & $\begin{array}{c}\mathrm{N}^{\circ} \text { of } \\
\text { subjects }\end{array}$ & Dose & Procedures & Conclusions \\
\hline Yang et al. & 2018 & $\begin{aligned} 88 \% & <5 \text { yrs; } 12 \% \\
& >5 \text { yrs }\end{aligned}$ & 17,948 & IND 2 mcg/kg + INK 1 mcg/kg & $\begin{array}{l}\text { Color Doppler ultrasound, } \\
\text { pulmonary function, and } \\
\text { EEG, MRI, ECG, ABR, fundus } \\
\text { examination, CT }\end{array}$ & $\begin{array}{l}\text { IND + INK: acceptable } \\
\text { effectiveness of procedural } \\
\text { sedation, low rates of } \\
\text { adverse events }\end{array}$ \\
\hline Liu et al. & 2018 & 0 to 3 yrs & 2,304 & IND 2 mcg/kg + INK 1 mg/kg & TTE & $\begin{array}{l}\text { IND + INK: effective } \\
\text { sedation with an acceptable } \\
\text { safety profile }\end{array}$ \\
\hline Ryan et al. & 2019 & $<18$ yrs & 546 & $\begin{array}{l}\text { INF } 2 \text { mcg/kg (max } 100 \mathrm{mcg}) \\
\text { INMDZ } 0.2 \text { mg/kg (max } 10 \mathrm{mg})\end{array}$ & Laceration reparation & $\begin{array}{l}\text { INF + INMDZ: safe and } \\
\text { effective analgosedation }\end{array}$ \\
\hline
\end{tabular}

IND, intranasal dexmedetomidine; CT, computerized tomography; ABR, auditory brainstem response; INK, intranasal ketamine; EEG, electroencephalography; MRI, magnetic resonance imaging; ECG, electrocardiography; MEG, magnetoencephalography.

Table 4 Dose of drugs administered intranasally

\begin{tabular}{lcl}
\hline Drug & $\begin{array}{c}\text { Dose per KG body } \\
\text { weight }\end{array}$ & \multicolumn{1}{c}{ Effect } \\
\hline Fentanyl & $1.5-2 \mu \mathrm{g} / \mathrm{kg}$ & Analgesic \\
Midazolam & $0.2-0.5 \mathrm{mg} / \mathrm{kg}$ & Sedative \\
Ketamine & $0.5-4 \mathrm{mg} / \mathrm{kg}$ & $\begin{array}{l}\text { Analgesic and } \\
\text { sedative }\end{array}$ \\
& $0.5-4 \mu \mathrm{g} / \mathrm{kg}$ & $\begin{array}{l}\text { Analgesic, sedative } \\
\text { and anxiolytic }\end{array}$ \\
\hline
\end{tabular}

All studies describe the use of different drugs, which analgesic and sedative effects, administered IN route in emergency settings in pediatric age. These are used for the management of acute pain in children subjected to different procedures, such as laceration repair, extremities fractures, incision and drainage, dental services, but also simply the placement of an IV catheter or diagnostic imaging execution.

The medication studied in all these papers were: midazolam, fentanyl, ketamine and dexmedetomidine. The dose of every 
single drug dispensed nasally is summarized in Table 4 .

\section{Fentanyl}

Fentanyl is a potent opioid with a quick onset of action along, with minimal sedation and impact on hemodynamic stability; it is effective for the management of acute moderate to severe pain in pediatric patients (9). It is well absorbed by the nasal mucosa because it has very high lipophilicity and low molecular weight (19). Generally, this drug is administered nasally at the dose of $1.5-2 \mu \mathrm{g} / \mathrm{kg}$. Yenigun et al. conducted a prospective study to demonstrate the major efficacy of IN fentanyl and ketamine, compared to IV paracetamol, for postoperative pain relief after pediatric tonsillectomy (20).

Besides, in literature different clinical trials compared the use of IN fentanyl vs. IN ketamine for the pain reduction due to fractures in children. All concluded that fentanyl provides effective analgesia as well as ketamine in relieving pain 20 minutes after administration. Quinn et al. demonstrated that IN fentanyl was superior to IN ketamine in relieving pain at 10 minutes (21). However, IN ketamine had a greater risk of adverse events (AE) than fentanyl, even if they are negligible and transient (22). Reynolds et al. stated that the number of $\mathrm{AE}$ was 2.2 times higher in the ketamine group than in the Fentanyl group, even if no serious adverse event (SAE) was observed. The most common side effect of ketamine was bad taste in the mouth, dizziness and sleepiness, while those of fentanyl were sleepiness, bad taste in the mouth and itchy nose (23).

Ryan $e t$ al., in a retrospective study, proved the most efficacy and safety of IN fentanyl used in combination with IN midazolam during laceration repair and no serious $\mathrm{AE}$ reported (24).

In 2019, Nemeth et al. (25) developed a protocol for acute pain therapy (APT) and urgent analgesia/sedation (UAS) in PED. The median time onset of drug action was 5 minutes. Fentanyl was most frequently used for APT, with pain scores decreased by a median of 4 points, while s-ketamine/midazolam was most frequently used for UAS. They did not report any serious AE.

Despite the proven sedative efficacy of IN fentanyl and the poor side effects, many physicians still have various concerns about its use in emergency departments. In 2018, Arnautovic et al., in a retrospective study, evaluated physician comfort and knowledge regarding the use of IN fentanyl for pain management in patients with long-bone fractures. They concluded that despite the implementation of a clinical IN fentanyl pain pathway, their pediatric ED continued to have frequently missed opportunities to administer IN fentanyl (26).

Seith et al. (27) in 2012, administered a continuous flow of nitrous oxide of $50 \%$ to $70 \%$ via a full-face mask in association IN fentanyl (dose of $1.5 \mu \mathrm{g} / \mathrm{kg}$ ). A nitrous oxide $\left(\mathrm{N}_{2} \mathrm{O}\right)$ alone agent has been associated with higher levels of emesis, but in combination with IN fentanyl, the incidence of vomiting is reduced.

In 2019, Seiler et al. (28) proved that there were no differences with regard to the analgesic efficacy, sedation depth and rate of $\mathrm{AE}$ of procedural analgo-sedation (PAS) in patients treated with $\mathrm{N}_{2} \mathrm{O} 70 \%$ with and without IN fentanyl.

\section{Midazolam}

Midazolam is a sedative that helps achieve anxiolysis and amnesia and it has been shown to be both safe and efficacious for pre-procedural sedation in the PED (8). It can be administered orally, nasally, rectally, IV or intramuscularly (IM). Shapiro et al. (29) showed that midazolam spray offers relief to children anxious about minor medical procedures, such as insertion of a needle in a subcutaneously implanted intravenous port, venous blood sampling and venous cannulation.

The dose of IN midazolam used in the different studies ranges between 0.2 and $0.5 \mathrm{mg} / \mathrm{kg}(8,18,30,31)$.

A triple-blind, randomized, controlled trial conducted by Joji Sado-Filho in 2019 (31), reported that the ketaminemidazolam combination appeared to be more effective in managing the behaviour of non-cooperative children, during dental treatment, in comparison to midazolam alone.

Besides, Brown et al. showed, in a retrospective study, that in children with autism spectrum disorders in ED, the most common sedatives used were IV ketamine and IN midazolam (32).

The most common adverse effects reported following IN midazolam is irritation in the nose, a bitter taste in the mouth and vomit. However, Midazolam can determine also respiratory and circulatory depression, but these side effects are not frequent when it is used alone.

Alp et al. (33) compared IN ketamine, IN midazolam, and oral chloral hydrate for children undergoing transthoracic echocardiography and concluded that all three agents provide adequate sedation, but IN midazolam has a more rapid onset of sedation while IN ketamine has a shorter duration of sedation. 
Besides, in literature, there are no particular indications on the timing of lasting from solids and liquids to keep children in view of the IN administration of sedative drugs.

However, in 2018, Malia et al. (30) in a prospective, observational study, showed that short nil per os (NPO) of both solids and liquids are safe for the use of IN midazolam, with a median time of $172.5 \mathrm{~min}$ for liquid and $194 \mathrm{~min}$ for solids.

\section{Ketamine}

Ketamine is a phencyclidine derivative with sedative and analgesic effects (34). It can cause cardiovascular effects, such as hypertension, tachycardia, but preserves cardiac output and therefore is often used in patients with hypovolemia or haemodynamic disorders (35). Ketamine is usually administered intravenously (IV) or IM, but it may also be administered intranasally (36). The oral, sublingual and rectal route may be possible but have poor bioavailability (37). IN ketamine is a safe and fast-acting sedation drug in children, takes effect after approximately 5-10 min and preserves respiratory activity (38). Unlike opioids, ketamine administration does not release histamine, which can promote nasal itching and congestion. This feature makes it a perfect sedative for asthmatics (39).

As already stated, the association of ketamine and midazolam appears to be more effective in managing the behavior of uncooperative children (31).

Besides, IN ketamine provides adequate analgesia similar to fentanyl in relieving moderate to severe pain in children. However, ketamine has more AE that are minor and transient, like a bad taste in the mouth, dizziness and sleepiness (21-23).

Nielsen et al. (40) studied the association of ketamine with sufentanil administered intranasally. The combination provides rapid onset of analgesia for a variety of painful procedures with few adverse effects, no desaturation and no change in heart rate.

Furthermore, combined with dexmedetomidine, IN ketamine seems to be an effective and safe sedative, with no severe adverse reaction, in particular during diagnostic examinations, as color-doppler ultrasound, pulmonary function, EEG, MRI, ECG, ABR, fundus examination, CT scan and transthoracic echocardiography $(35,41)$.

\section{Dexmedetomidine}

Dexmedetomidine is a highly selective alpha-2 adrenergic agonist with sedative, anxiolytic, and analgesic properties. It can be administered by the intravenous, intramuscular, oral or IN route. IN dexmedetomidine is becoming useful, especially for short procedures that require the child to be sedated. It is odorless and tasteless, and no published study on this drug reported neither nausea nor vomiting. Dexmedetomidine induces sleep similar to natural sleep. Thus, even with high dose IN dexmedetomidine, external stimuli may easily awake patients. Dexmedetomidine can be used in varying doses, from 0.5 to $4 \mu \mathrm{g} / \mathrm{kg}$, depending on the level of sedation required. A higher dose produces a deeper level of sedation, which may improve procedural success. Dexmedetomidine has minimal respiratory depression and acceptable cardiovascular effects, such as hypertension, hypotension, and bradycardia (42). As the level of sedation, a decrease in heart rate is also dosedependent (43). A case report describes a healthy pediatric patient who developed symptomatic bradycardia lasting two hours after IN dexmedetomidine sedation (44).

Furthermore, in some studies, dexmedetomidine has neuroprotective properties, reducing apoptosis in animals and humans (45-48).

According to Patel et al., dexmedetomidine may perform safe and effective sedation in children, and the IN route is far superior to the oral administration (49). IN dexmedetomidine is more rapidly absorbed in blood stems compared to the oral form, and it preserves the airway reflexes and respiratory drive (13).

IND has the same sedation power for imaging study if compared to oral chloral hydrate; in addition, IND has fewer gastrointestinal adverse effects during drug administration, less hypotension and hypoxia requiring oxygen therapy, but more bradycardia (50).

In 2019, Sathyamoorthy et al. (51), comparing IND to oral midazolam in difficult children, subjected to dental procedures, concluded that IND provides a higher success rate in sedation and parental separation. Otherwise, according to Li et al. (52), the combination of IND and oral midazolam has a higher sedation success rate than the IND solo for CT and/or ABR study in children with autistic spectrum disorders, without an increase in adverse effects. Some studies investigated the association of IN dexmedetomidine and ketamine. In 2019, Oriby (53) compared the effects of combined IN dexmedetomidine and oral ketamine versus IN midazolam as sedative premedication for children undergoing dental rehabilitation procedures. He found that the combination has a significantly more satisfactory and rapid onset of sedation, 
with more postoperative analgesia and less postoperative shivering in comparison with IN midazolam.

A retrospective observational study conducted by Liu et al. (35) assessed the effectiveness and the security of IN dexmedetomidine combined with IN ketamine as sedation for young children during transthoracic echocardiography. They found a sedation success rate of $96 \%$ and an onset time of sedation of $15.7 \mathrm{~min}$ (IQR, 10-23 min). Similar values are found by Yang et al. (41), who retrospectively analyzed a sample of 17,948 pediatric patients undergoing procedural sedation with a combination of IN dexmedetomidine and ketamine. The association has a sedation success rate of $93 \%$, with $15 \mathrm{~min}$ (IQR, 15-20 $\mathrm{min}$ ) time for onset and a median sedation time of $62 \mathrm{~min}$ (IQR, 55-70 $\mathrm{min}$ ). The lower rates of AE, in particular, bradycardia or hypotension, than those in previous studies of dexmedetomidine sedation (54-55) may be related to the combined use of ketamine. Some studies reported there was less hypotension when ketamine was added to dexmedetomidine $(56,57)$.

\section{Discussion}

Many procedures, both for diagnostic purposes, such as urine sampling and lumbar punctures, and therapeutic purposes, such as intravenous insertion, wound/burn management and orthopaedic trauma can cause pain, anxiety and stress to the child admitted to the Pediatric Emergency Room. Furthermore, some diagnostic exams, like echocardiography, CT scan, MRI, require the child to don't move. In this setting, the procedural sedation has become a helpful tool for the clinician trained for managing analgosedation, and a good ally for the child and his parents, reducing children's pain and suffering, and parent's worries. Intravenous sedation, as it involves the use of needles, can be stressful itself. For that reason, in recent years the use of the IN route is becoming more widespread as it is essentially painless and effective. Some drugs may be administered by a mucosal atomizer dispositive (MAD) or by drops. When available, the use of a MAD is preferable, since drops are primarily deposited on the ciliary surface with excess runoff down the throat. The advantages of atomized delivery include less drug loss to the oropharynx, higher cerebrospinal fluid drug levels, better patient acceptability and improved sedative effects $(58,59)$. In literature are not particular indications on the timing of lasting from solids and liquids for children in view of the administration of sedative drugs intranasally. However, if possible, it is always preferable to keep the child on an empty stomach in the previous 2-3 hours.

IN midazolam is the most commonly used and studied sedative drug in pediatric patients. It has sedative, anxiolytic, and amnesic effects, but no analgesic properties, so it can be used for minor medical procedures. IN administration can cause nasal irritation and bitter taste in the mouth, while other side effects, such as respiratory and circulatory depression, are infrequent. In literature, there are many data also about other drugs administered intranasally, such as fentanyl, ketamine, and dexmedetomidine. Fentanyl and ketamine are used especially for their pain controlling action. It's been demonstrated that they both provide effective analgesia in children with moderate to severe pain when administered intranasally. The advantage of using ketamine lies in the fact that, unlike opioids, it does not release histamine, avoiding nasal itching and congestion. A relatively new drug studied in IN pediatric procedural sedation is dexmedetomidine. It has some properties that make it a tempting option. IN dexmedetomidine is odourless and tasteless, has minimal respiratory depression and acceptable cardiovascular effects; it is sedative, anxiolytic, and analgesic and some studies showed her neuroprotective effect, reducing apoptosis both in animals and humans (45-48).

However, a multimodal analgesic regimen provides better pain control and functional outcome in children and cooperation (60).

\section{Conclusions}

IN analgosedation is a simple, rapid and painless option to prevent and treat the pain and anxiety in the Pediatric Emergency Department. It needs a brief training about the administration method and experience in sedation. The choice of the right drug depends on the contraindications and the type of procedure the child must undergo. We hope that our review could contribute to spread the acknowledgement about IN sedative drugs and to increase their use in every child who must undergo to some stressful or painful procedure.

\section{Acknowledgments}

Funding: None.

\section{Footnote}

Provenance and Peer Review: This article was commissioned 
by the Guest Editor (Dr. Antonio Ruggiero) for the series "Pain Therapy" published in Annals of Translational Medicine. The article was sent for external peer review organized by the Guest Editor and the editorial office.

Reporting Checklist: The authors have completed the Narrative Review reporting checklist. Available at http:// dx.doi.org/10.21037/atm-20-5177

Conflicts of Interest: All authors have completed the ICMJE uniform disclosure form (available at http://dx.doi. org/10.21037/atm-20-5177). The series "Pain Therapy" was commissioned by the editorial office without any funding or sponsorship. AR served as the unpaid Guest Editor of the series and serves as an unpaid editorial board member of Annals of Translational Medicine from Nov 2019 to Oct 2021. The other authors have no other conflicts of interest to declare.

Ethical Statement: The authors are accountable for all aspects of the work in ensuring that questions related to the accuracy or integrity of any part of the work are appropriately investigated and resolved.

Open Access Statement: This is an Open Access article distributed in accordance with the Creative Commons Attribution-NonCommercial-NoDerivs 4.0 International License (CC BY-NC-ND 4.0), which permits the noncommercial replication and distribution of the article with the strict proviso that no changes or edits are made and the original work is properly cited (including links to both the formal publication through the relevant DOI and the license). See: https://creativecommons.org/licenses/by-nc-nd/4.0/.

\section{References}

1. Oliveira NC, Santos JL, Linhares MB. Audiovisual distraction for pain relief in paediatric inpatients: A crossover study. Eur J Pain 2017;21:178-87.

2. Wilson JE, Pendleton JM. Oligoanalgesia in the emergency department. Am J Emerg Med 1989;7:620-3.

3. Hennes H, Kim MK, Pirrallo RG. Prehospital pain management: a comparison of providers' perceptions and practices. Prehosp Emerg Care 2005;9:32-9.

4. Schechter NL. The undertreatment of pain in children: an overview. Pediatr Clin North Am 1989;36:781-94.

5. de Freitas GR, De Castro CG Jr, Castro SM, et al. Degree of knowledge of health care professionals about pain management and use of opioids in pediatrics. Pain Med 2014;15:807-19.

6. Saroyan JM, Schechter WS, Tresgallo ME, et al. Assessing resident knowledge of acute pain management in hospitalized children: a pilot study. J Pain Symptom Manage 2008;36:628-38.

7. Fosnocht DE, Swanson ER, Barton ED. Changing attitudes about pain and pain control in emergency medicine. Emerg Med Clin North Am 2005;23:297-306.

8. Lane RD, Schunk JE. Atomized intranasal midazolam use for minor procedures in the pediatric emergency department. Pediatr Emerg Care 2008;24:300-3.

9. Cole J, Shepherd M, Young P. Intranasal fentanyl in 1-3-year-olds: a prospective study of the effectiveness of intranasal fentanyl as acute analgesia. Emerg Med Australas 2009;21:395-400.

10. Del Pizzo J, Callahan JM. Intranasal medications in pediatric emergency medicine. Pediatr Emerg Care 2014;30:496-501.

11. Almenrader N, Passariello $M$, Coccetti B, et al. Premedication in children: a comparison of oral midazolam and oral clonidine. Paediatr Anaesth 2007;17:1143-9.

12. Feng JF, Wang XX, Lu YY, et al. Effects of dexmedetomidine versus midazolam for premedication in paediatric anaesthesia with sevoflurane: A meta-analysis. J Int Med Res 2017;45:912-23.

13. Talon MD, Woodson LC, Sherwood ER, et al. Intranasal dexmedetomidine premedication is comparable with midazolam in burn children undergoing reconstructive surgery. J Burn Care Res 2009;30:599-605.

14. Kanegaye JT, Favela JL, Acosta M, et al. High-dose rectal midazolam for pediatric procedures: a randomized trial of sedative efficacy and agitation. Pediatr Emerg Care 2003;19:329-36.

15. Salib RJ, Harries PG, Nair SB, et al. Mechanisms and mediators of nasal symptoms in non-allergic rhinitis. Clin Exp Allergy 2008;38:393-404.

16. Grassin-Delyle S, Buenestado A, Naline E, et al. Intranasal drug delivery: an efficient and non-invasive route for systemic administration: focus on opioids. Pharmacol Ther 2012;134:366-79.

17. Wolfe TR, Braude DA. Intranasal medication delivery for children: a brief review and update. Pediatrics 2010;126:532-7.

18. Chiaretti A, Barone G, Rigante D, et al. Intranasal lidocaine and midazolam for procedural sedation in children. Arch Dis Child 2011;96:160-3.

19. Kress HG, Orońska A, Kaczmarek Z, et al. Efficacy and 
tolerability of intranasal fentanyl spray 50 to 200 microg for breakthrough pain in patients with cancer: a phase III, multinational, randomized, double-blind, placebocontrolled, crossover trial with a 10-month, open-label extension treatment period. Clin Ther 2009;31:1177-91.

20. Yenigun A, Yilmaz S, Dogan R, et al. Demonstration of analgesic effect of intranasal ketamine and intranasal fentanyl for postoperative pain after pediatric tonsillectomy. Int J Pediatr Otorhinolaryngol 2018;104:182-5.

21. Quinn K, Kriss S, Drapkin J, et al. Analgesic Efficacy of Intranasal Ketamine Versus Intranasal Fentanyl for Moderate to Severe Pain in Children: A Prospective, Randomized, Double-Blind Study. Pediatr Emerg Care 2018. [Epub ahead of print].

22. Frey TM, Florin TA, Caruso M, et al. Effect of Intranasal Ketamine vs Fentanyl on Pain Reduction for Extremity Injuries in Children: The PRIME Randomized Clinical Trial. JAMA Pediatr 2019;173:140-6.

23. Reynolds SL, Bryant KK, Studnek JR, et al. Randomized Controlled Feasibility Trial of Intranasal Ketamine Compared to Intranasal Fentanyl for Analgesia in Children with Suspected Extremity Fractures. Acad Emerg Med 2017;24:1430-40.

24. Ryan PM, Kienstra AJ, Cosgrove P, et al. Safety and effectiveness of intranasal midazolam and fentanyl used in combination in the pediatric emergency department. Am J Emerg Med 2019;37:237-40.

25. Nemeth M, Jacobsen N, Bantel C, et al. Intranasal Analgesia and Sedation in Pediatric Emergency Care-A Prospective Observational Study on the Implementation of an Institutional Protocol in a Tertiary Children's Hospital. Pediatr Emerg Care 2019;35:89-95.

26. Arnautovic T, Sommese K, Mullan PC, et al. Evaluating the Implementation Barriers of an Intranasal Fentanyl Pain Pathway for Pediatric Long-Bone Fractures. Pediatr Emerg Care 2018;34:473-8.

27. Seith RW, Theophilos T, Babl FE. Intranasal fentanyl and high-concentration inhaled nitrous oxide for procedural sedation: a prospective observational pilot study of adverse events and depth of sedation. Acad Emerg Med 2012;19:31-6.

28. Seiler M, Staubli G, Landolt MA. Combined nitrous oxide $70 \%$ with intranasal fentanyl for procedural analgosedation in children: a prospective, randomised, double-blind, placebo-controlled trial. Emerg Med J 2019;36:142-7.

29. Shapiro F, Athiraman U, Clendenin DJ, et al. Anesthetic management of 877 pediatric patients undergoing muscle biopsy for neuromuscular disorders: a 20-year review. Paediatr Anaesth 2016;26:710-21.

30. Malia L, Laurich VM, Sturm JJ. Adverse events and satisfaction with use of intranasal midazolam for emergency department procedures in children. Am J Emerg Med 2019;37:85-8.

31. Sado-Filho J, Viana KA, Corrêa-Faria P, et al. Randomized clinical trial on the efficacy of intranasal or oral ketamine-midazolam combinations compared to oral midazolam for outpatient pediatric sedation. PLoS One 2019;14:e0213074.

32. Brown JJ, Gray JM, Roback MG, et al. Procedural sedation in children with autism spectrum disorders in the emergency department. Am J Emerg Med 2019;37:1404-8.

33. Alp H, Elmacı AM, Alp EK, et al. Comparison of intranasal midazolam, intranasal ketamine, and oral chloral hydrate for conscious sedation during paediatric echocardiography: results of a prospective randomised study. Cardiol Young 2019;29:1189-95.

34. Green SM, Johnson NE. Ketamine sedation for pediatric procedures: Part 2, Review and implications. Ann Emerg Med 1990;19:1033-46.

35. Liu J, Du M, Liu L, et al. Sedation effects of intranasal dexmedetomidine combined with ketamine and risk factors for sedation failure in young children during transthoracic echocardiography. Paediatr Anaesth 2019;29:77-84.

36. Poonai N, Canton K, Ali S, et al. Intranasal ketamine for procedural sedation and analgesia in children: A systematic review. PLoS One 2017;12:e0173253.

37. Peltoniemi MA, Hagelberg NM, Olkkola KT, et al. Ketamine: A Review of Clinical Pharmacokinetics and Pharmacodynamics in Anesthesia and Pain Therapy. Clin Pharmacokinet 2016;55:1059-77.

38. JH Diaz. Intranasal ketamine preinduction of paediatric outpatients. Paediatr Anaesth 1997;7:273-8.

39. White PF, Way WL, Trevor AJ. Ketamine-its pharmacology and therapeutic uses. Anesthesiology 1982;56:119-36.

40. Nielsen BN, Friis SM, Rømsing J, et al. Intranasal sufentanil/ketamine analgesia in children. Paediatr Anaesth 2014;24:170-80.

41. Yang F, Liu Y, Yu Q, et al. Analysis of 17948 pediatric patients undergoing procedural sedation with a combination of intranasal dexmedetomidine and ketamine. Paediatr Anaesth 2019;29:85-91.

42. Zhang W, Wang Z, Song X, et al. Comparison of rescue techniques for failed chloral hydrate sedation for magnetic resonance imaging scans-additional chloral 


\section{Page 10 of 10}

hydrate vs intranasal dexmedetomidine. Paediatr Anaesth 2016;26:273-9.

43. Mason KP, Lerman J. Review article: Dexmedetomidine in children: current knowledge and future applications. Anesth Analg 2011;113:1129-42.

44. Patel VJ, Ahmed SS, Nitu ME, et al. Vasovagal syncope and severe bradycardia following intranasal dexmedetomidine for pediatric procedural sedation. Paediatr Anaesth 2014;24:446-8.

45. Sanders RD, Sun P, Patel S, et al. Dexmedetomidine provides cortical neuroprotection: impact on anaestheticinduced neuroapoptosis in the rat developing brain. Acta Anaesthesiol Scand 2010;54:710-6.

46. Li Y, Zeng M, Chen W, et al. Dexmedetomidine reduces isoflurane-induced neuroapoptosis partly by preserving PI3K/Akt pathway in the hippocampus of neonatal rats. PLoS One 2014;9:e93639.

47. Tachibana K, Hashimoto T, Kato R, et al. Neonatal administration with dexmedetomidine does not impair the rat hippocampal synaptic plasticity later in adulthood. Pediatric Anesthesia 2012;22:713-9.

48. Sanders RD, Xu J, Shu Y, et al. Dexmedetomidine attenuates isoflurane-induced neurocognitive impairment in neonatal rats. Anesthesiology 2009;110:1077-85.

49. Patel V, Singh N, Saksena AK, et al. A comparative assessment of intranasal and oral dexmedetomidine for procedural sedation in pediatric dental patients. J Indian Soc Pedod Prev Dent 2018;36:370-5.

50. Yuen VMY, Cheuk DKL, Hui TWC, et al. Oral chloral hydrate versus intranasal dexmedetomidine for sedation of children undergoing computed tomography: a multicentre study. Hong Kong Med J 2019;25 Suppl 3:27-9.

51. Sathyamoorthy M, Hamilton TB, Wilson G, et al. Premedication before dental procedures: A randomized controlled study comparing intranasal dexmedetomidine with oral midazolam. Acta Anaesthesiol Scand 2019;63:1162-8.

Cite this article as: Pansini V, Curatola A, Gatto A, Lazzareschi I, Ruggiero A, Chiaretti A. Intranasal drugs for analgesia and sedation in children admitted to pediatric emergency department: a narrative review. Ann Transl Med 2021;9(2):189. doi: 10.21037/atm-20-5177

\section{Pansini et al. IN analgosedation in Pediatric Emergency Department}

52. Li BL, Yuen VM, Zhang N, et al. A Comparison of Intranasal Dexmedetomidine and Dexmedetomidine Plus Buccal Midazolam for Non-painful Procedural Sedation in Children with Autism. J Autism Dev Disord 2019;49:3798-806.

53. Oriby ME. Comparison of Intranasal Dexmedetomidine and Oral Ketamine Versus Intranasal Midazolam Premedication for Children Undergoing Dental Rehabilitation. Anesth Pain Med 2019;9:e85227.

54. Baier NM, Mendez SS, Kimm D, et al. Intranasal dexmedetomidine: an effective sedative agent for electroencephalogram and auditory brain response testing. Paediatr Anaesth 2016;26:280-5.

55. Mason KP, Zgleszewski SE, Prescilla R, et al. Hemodynamic effects of dexmedetomidine sedation for CT imaging studies. Paediatr Anaesth 2008;18:393-402.

56. Qiao H, Xie Z, Jia J. Pediatric premedication: a doubleblind randomized trial of dexmedetomidine or ketamine alone versus a combination of dexmedetomidine and ketamine. BMC Anesthesiol 2017;17:158.

57. Mester R, Easley RB, Brady KM, et al. Monitored Anesthesia Care With a Combination of Ketamine and Dexmedetomidine During Cardiac Catheterization. Am J Ther 2008;15:24-30.

58. Pandey RK, Bahetwar SK, Saksena AK, et al. A comparative evaluation of drops versus atomized administration of intranasal ketamine for the procedural sedation of young uncooperative pediatric dental patients: a prospective crossover trial. J Clin Pediatr Dent 2011;36:79-84.

59. Primosch RE, Guelmann M. Comparison of drops versus spray administration of intranasal midazolam in two- and three-year-old children for dental sedation. Pediatr Dent 2005;27:401-8.

60. Chiaretti A, Pierri F, Valentini P, et al. Current practice and recent advances in pediatric pain management. Eur Rev Med Pharmacol Sci 2013;17 Suppl 1:112-26. 